Goldschmidt 2021 Abstract

https://doi.org/10.7185/gold2021.3474

\section{Mechanistic elucidation of abiotic monomethylmercury photodemethylation in freshwaters: Experimental evidence}

\author{
ELAHEH LOTFI KALAHROODI ${ }^{1}$, EMMANUEL \\ TESSIER $^{2}$, MICKAEL LE BECHEC ${ }^{2}$, SYLVAIN BÉRAIL ${ }^{2}$, \\ THIERRY PIGOT ${ }^{2}$ AND DAVID AMOUROUX ${ }^{3}$ \\ ${ }^{1}$ CNRS,Universite de Pau et des Pays de l'Adour, E2S UPPA, \\ CNRS, IPREM, Institut des Sciences Analytiques et de Physico- \\ chimie pour l'Environnement et les matériaux \\ ${ }^{2}$ Universite de Pau et des Pays de l'Adour, E2S UPPA, CNRS, \\ IPREM, Institut des Sciences Analytiques et de Physico-chimie \\ pour l'Environnement et les matériaux, Pau \\ ${ }^{3}$ CNRS, Université de Pau et Pays de l'Adour, E2S UPPA, \\ IPREM
}

Presenting Author: elaheh.lotfi-kalahroodi@univ-pau.fr

Mechanistic elucidation of abiotic monomethylmercury photodemethylation in freshwaters: Experimental evidence

Inorganic mercury (iHg) and monomethylmercury $(\mathrm{MMHg})$ can accumulate in aquatic organisms and $\mathrm{MMHg}$ biomagnifies along the trophic chain, presenting a hazard to higher consumers, including humans. The MMHg decomposition can be abiotically induced by photodegradation in the water column or biotically by certain microorganisms. Our aim in this work was to elucidate the abiotic photodemethylation pathway in model freshwater (Fulvic Acids organic matter - SRFA with DOC $=6 \mathrm{ppm}$, and $[\mathrm{MMHg}]=50 \mathrm{ppb}$ at $\mathrm{pH} 6.5)$. We, therefore, irradiated $\mathrm{MMHg}$ freshwater solution through exposure to the solar spectrum (e.g. 280-800 $\mathrm{nm}$ ) and performed kinetic experiments following $\mathrm{Hg}$ species concentrations (iHg(II), MMHg, $\mathrm{Hg}(0)$ ). Dissolved gaseous mercury $(\mathrm{Hg}(0))$ was trapped continuously purging with pure air and/or Argon (Ar). The role of oxygen was evaluated for MMHg photodemethylation rate and $\mathrm{Hg}(0)$ photo-oxidation. In addition, reactive oxygen species (ROS) production was evaluated by chemical quenching tests; and mass-dependent fractionation (MDF) and mass-independent fractionation (MIF) of $\mathrm{Hg}$ stable isotopes (expressed as $\delta^{202} \mathrm{Hg}$, and $\Delta^{199} \mathrm{Hg}$ ), were measured in the freshwater solution.

In all experiments, $>50 \%$ of photodemethylated $\mathrm{MMHg}$ was transformed to $\operatorname{Hg}(0)$, regardless of purging gas. Unexpectedly, photodemethylation under Ar showed a higher kinetic rate and $\mathrm{Hg}(0) / \mathrm{iHg}(\mathrm{II})$ ratio than those with air saturation. Moreover, ROS test showed higher production of radical species under Ar. This experiment rejects the hypothesis of enhanced $\operatorname{Hg}(0)$ oxidation with higher $\mathrm{O}_{2}$ content. It also suggests that the occurrence of high $\mathrm{O}_{2}$ concentration may inhibit photodemethylation, preventing electron transfer between organic matter and/or redox-sensitive couples (i.e. iron). $\mathrm{MMHg}$ photodemethylation showed MDF within the range $\delta^{202} \mathrm{Hg}+0.25$ - + $0.30 \%$. Photodemethylation in Ar resulted in larger MIF with $\Delta^{199} \mathrm{Hg}=3.1 \%$, whereas, under air, MIF reached $1.7 \%$. Therefore, high $\mathrm{Hg}(0) / \mathrm{iHg}$ ratio during photodemethylation in $\mathrm{Ar}$ confirms that large MIF resulted from a complete photodemethylation and/or photoreduction of $\mathrm{iHg}(\mathrm{II})$ to $\operatorname{Hg}(0)$ pathways. This study highlights the role of oxygen in the inhibition of the photochemical pathways. These competitive mechanisms influence in turn the isotopic fractionation extent of $\mathrm{Hg}$ (MIF). The role of organic radicals and overlooked redox species will be further discussed. 